\title{
REFLEXÕES SOBRE O ESPAÇO, O URBANO E A URBANIZAÇÃO
}

\author{
ESTER LIMONAD \\ Universidade Federal Fluminense
}

\begin{abstract}
É nossa intenção discutir se a urbanização é passível de ser compreendida como parte integrante do processo geral de estruturação da sociedade e do território. Um processo onde as desigualdades geográficas, econômicas, sociais etc... conjugadas à mobilidade espacial e setorial do trabalho contribuem para alterar o território, subordinadas às necessidades de reprodução geral das relações sociais e espaciais de produção e ao desenvolvimento do meio técnico-científico. Este processo que gera fixos e fluxos tem uma resultante que se expressa espacialmente em duas escalas: a cidade, na escala dos lugares; e a rede urbana, enquanto a manifestação espacial da cooperação entre lugares (LOJKINE, 1981), na escala territorial. Isto não significa dizer que a urbanização em si seja um determinante maior ou menor, mas sim um elemento que interage com outros na construção do espaço, do urbano, que tende a ir além das cidades.

Trataremos, portanto, da estruturação do território sob um olhar particular, específico, todavia, ao mesmo tempo, amplo, concernente à urbanização enquanto necessidade histórica para a reprodução das relações sociais de produção numa formação social e econômica específica.
\end{abstract}

\section{Para uma concepção ampliada da urbanização}

A negligência com o espaço, enquanto categoria de análise, por parte da teoria social em geral, e pelas ciências sociais em particular (exceto por raras exceções das contribuições dos leninistas, de Gramsci e da Escola de Chicago) e o desinte- 
resse da Geografia para com as relações sociais de produção e com a análise dos fenômenos sociais e econômicos, até a década de 60 , deveu-se em boa parte à herança positivista de estanquização do conhecimento em diferentes competências. Portanto, se as ciências sociais, a economia e outros ramos do conhecimento não se preocuparam com a espacialidade das relações sociais de produção, foi porque não fazia parte das atribuições destes campos de conhecimento.

Algumas correntes de análise, todavia, não deixaram o espaço completamente de lado. Entre elas a ecologia urbana da Escola de Chicago; as proposições de planejamento urbano e regional que despontaram entre 1930/50; a historiografia regional e a produção dos Annales, que deu continuidade às tradições de Vidal de La Blache; as teorias marxistas do imperialismo e os trabalhos de Gramsci sobre a questão regional.

As abordagens que tentavam articular as categorias espaço-tempo questionavam as análises historicistas e economicistas vigentes. Estas abordagens encaravam o espaço apenas como um elemento cultural, e portanto integrante da superestrutura de uma sociedade e o urbano enquanto um mero somatório de elementos ou um espaço marginal à produção. Entre os pioneiros da articulação do tempo/espaço, em relação à urbanização, temos Henri Lefebvre, para quem o espaço não se resumiria a um reflexo das relações sociais de produção e a urbanização, por sua vez, enquanto processo de disseminação do urbano, que ampliava-se e generalizava-se em escala mundial - deveria ser entendida enquanto expressão das relações sociais ao mesmo tempo em que incidiria sobre elas (LEFEBVRE, 1972).

O significado dos termos urbano e urbanização para Lefebvre ia além dos limites das cidades. Em seu entender a urbanização seria uma condensação dos processos sociais e espaciais que haviam permitido ao capitalismo se manter e reproduzir suas relações essenciais de produção e a própria sobrevivência do capitalismo estaria baseada na criação de um espaço social crescentemente abrangente, instrumental e mistificado (LEFEBVRE, 1991), na compreensão de que "é neste espaço dialectizado (conflitual) que se realiza a reprodução das relações de produção. É este espaço que produz a reprodução das relações de produção, introduzindo nela contradições múltiplas, vindas ou não do tempo histórico”. (LEFEBVRE, 1973)

Pelo fato de Lefebvre colocar num mesmo plano o espaço social e as relações sociais de produção, muitos interpretaram isto como uma tentativa de atribuir um papel transformador ao espaço. Lefebvre, todavia, não confere ao espaço um papel transformador, mas condicionador, regulador como fica claro na seguinte passagem:

As práticas espaciais regulam a vida - não a criam. $O$ espaço não tem poder em 'si mesmo', nem o espaço enquanto tal determina as contradições espaciais. Estas são contradições da sociedade - contradições entre uma coisa e outra no interior da sociedade, como por 
exemplo entre as forças e as relações de produção - que simplesmente emergem no espaço, ao nível do espaço, e assim engendram as contradições do espaço (LEFEBVRE, 1974)

Para ele, assim, o espaço socialmente produzido assume um papel interativo com as relações sociais de produção. E a que relações sociais de produção Lefebvre se refere?

deve-se tomar como referência não a produção no sentido restrito dos economistas - isto é, o processo de produção das coisas e de seu consumo -, mas a reprodução das relaçães de produção. Nesta ampla acepção, o espaço da produção implicaria, portanto, e encerraria em seu seio a finalidade geral, a orientação comum a todas às atividades dentro da sociedade neocapitalista. Trata-se da produção no mais amplo sentido da palavra: produção das relações sociais e reprodução de determinadas relações · (LEFEBVRE, 1976)

Com isso sua proposição conquista uma amplitude maior do que a proposição de Castells, que reduziu o urbano a uma ideologização ao nível do consumo, enquanto um espaço marginal à produção.

A vinculação do espaço em geral e do espaço urbano em particular apenas à produção, segundo Lefebvre, implicaria apenas na reprodução dos meios de produção concernentes à força de trabalho e seria adequada a uma análise do capitalismo competitivo do século XIX e não à atual etapa. Por outro lado, desde então as condições gerais se transformaram, e hoje o sistema capitalista deve garantir sempre além da reprodução dos meios de produção, a reprodução das relações sociais de produção, efetivada através da totalidade do espaço, na medida em que compreendem a reprodução do cotidiano em novos e antigos espaços, perpassados por diferentes tempos históricos - simultaneidades.

Para Lefebvre a reprodução ampliada e as novas condições materiais do capitalismo estariam intimamente relacionadas aos processos pelos quais o sistema capitalista como um todo consegue ampliar sua existência através da manutenção e disseminação sócio-espacial de suas estruturas. Tanto a nível da reprodução do cotidiano, da reprodução da força de trabalho e dos meios de produção quanto a nível da reprodução das condições gerais e das relações gerais sociais de produção, onde a organização do espaço passa a desempenhar um papel fundamental. Seria no espaço socialmente produzido, o espaço urbano do capitalismo mesmo no campo, onde se reproduziriam as relações dominantes de produção através de um espaço social concretizado, criado, ocupado e fragmentado conforme as necessidades da produção e do capitalismo.

Nossa intenção é trabalhar a compreensão do espaço conjugada à urbanização, a qual sugere um corte analítico onde a tradicional distinção entre abordagens disciplinares será absorvida por uma diferenciação epistemológica. Esta última é mais 
genérica e fundamental e abriga uma discussão que ultrapassa o recorte disciplinar, pois se a discussão sobre a urbanização é teórica, o debate sobre o espaço situa-se no campo epistemológico, por este não se constituir em um conceito, mas em uma categoria do conhecimento.

Não é nossa intenção, todavia, proceder a uma discussão exaustiva e aprofundada. Isto já foi feito de diferentes maneiras, com distintos recortes por diversos autores (Castells, Harvey, Soja e Lefebvre entre outros). Iremos, outrossim, selecionar exemplos representativos das diversas concepções para explicitar porque entendemos a urbanização enquanto parte do processo de estruturação do território, enquanto um processo histórico-espacial com desdobramentos sócio-econômicos.

\section{A vertente crítica}

Elaborada desde o século XIX a partir da obra de Marx, a abordagem crítica viu-se perante um desafio na medida em que a ampliação do capitalismo resultou no surgimento de novas condições de reprodução das sociedades capitalistas no século XX. A cidade e a urbanização tornaram-se um enigma a ser desvendado e um desafio para o "paradigma" crítico de filiação marxista; tratava-se de encontrar uma resposta política apropriada a uma urbanização crescente da economia e da vida social e política em todos os aspectos e escalas.

Até a década de 70 pouca atenção se deu, no âmbito da teoria crítica, à questão do espaço propriamente dito. O espaço era visto como um continente ou um reflexo externo da dinâmica social, que seria neutralizado em termos de sua interação com os processos sociais e históricos.

A produção teórica a partir da década de 70 , sobre o espaço e a urbanização, tanto a estruturalista quanto a de reação ao positivismo estruturalista, corporificouse em uma economia política da urbanização e do desenvolvimento. A interdisciplinaridade epistemológica levou a diferentes conceituações e definições do espaço e do urbano e à percepção das mudanças da urbanização conforme o capitalismo se ampliava e avançava, num constante processo de reestruturação e globalização.

A cidade foi descoberta, inicialmente, como locus, espaço, de reprodução da força de trabalho, da troca e do consumo. O planejamento urbano foi criticamente examinado como instrumento de coerção e normatização do espaço pelo Estado. A atenção dos analistas transferiu-se dos locais de trabalho (fábricas) para os conflitos nos locais de reprodução e sobrevivência da força de trabalho (meio urbano, habitação e equipamentos coletivos e serviços de infra-estrutura) que se consolidaram em diversos estudos sobre os movimentos sociais urbanos reificados como a nova forma de luta política por diversos estudiosos. Isto contribuiu para ampliar o 
campo da análise urbana em diversos segmentos preocupados principalmente com a reprodução da força de trabalho e o consumo coletivo.

\section{Trajetória e principais contribuições}

O historicismo na ciência social tradicional assumiu muitas versões distintas e em todas a questão do espaço permanecia como um apêndice ou complicação. A postura historicista tendia a bloquear o papel do espaço social na estruturação do território e a transformá-lo no lugar do processo histórico. Igualmente, na vertente crítica, os trabalhos de cunho historicista centraram-se na dinâmica temporal e ignoraram a dinâmica espacial da modernização e do modernismo, a despeito das contribuições de Lenin (1913-1916), Luxemburgo (1972), Trotski (1978) para uma teoria do desenvolvimento histórico e geograficamente desigual e combinado.

Os trabalhos de cunho economicista contribuíram para minimizar tanto a reificação espacial fascista, inspirada num hipotético determinismo geográfico de Ratzel, quanto a reificação do espaço proposta por Le Corbusier. Propiciaram, também, que toda formulação que procurasse associar a dimensão espacial à teoria social crítica fosse descartada enquanto um fetichismo do espaço e privilegiamento de uma falsa consciência, própria do idealismo hegeliano, postura que se manteve até os anos 70 .

De certa forma a recuperação da discussão do espaço na teoria crítica deve-se em parte às contribuições do existencialismo marxista de Sartre e do estruturalismo de Althusser, ambas abertas para a questão do espaço e que por seu antagonismo no concernente à relação estrutura-sujeito contribuíram para cindir o marxismo francês após 1945 .

A abordagem estruturalista inspirou diversos estudos sobre o espaço no âmbito de vários corpos disciplinares, por fornecer um corpo epistemológico que permitia discutir as raízes dos fenômenos e efeitos espaciais nas relações sociais de produção, em particular por seus ataques ao historicismo e por sua abertura para a questão espacial. Esta abordagem contribuiu para as formulações de Castells, para a geografia marxista nascente se contrapor aos estudos positivistas e para abrir brechas no arcabouço anti-espacial elaborado pelos adeptos do historicismo e do economicismo.

Após analisar a produção teórica relativa à urbanização Castells define-a enquanto uma noção ideológica (CASTELLS, 1978); ${ }^{1}$ por partir da proposição que

\footnotetext{
1 “....a noção ideológica de urbanização refere-se ao processo através do qual uma proporção significativamente importante da população de uma sociedade se concentra em um certo espaço, no qual se constituem aglomerações funcional e socialmente interdependentes do ponto de vista interno, e em relação de articulação hierarquizada (rede urbana).” (CASTELLS, 1978)
} 
esta refere-se tanto a formas espaciais quanto a um sistema cultural específico, de onde conseqüentemente não haveria uma problemática especificamente urbana. Descarta-a, assim, enquanto objeto de estudo e propõe que "mais que falar de urbanização, trataremos do tema da produção social de formas espaciais" (CASTELLS, 1978), e reduz o urbano ao espaço funcional onde se concentra uma população.

Atribuir uma especificidade ao urbano, em seu entender, equivaleria a recair na ideologia da escola de Chicago, base de sua crítica a Lefebvre. Pois isto significaria tanto "estabelecer a correspondência entre formas ecológicas e conteúdo cultural" quanto "sugerir uma ideologia da produção de valores sociais a partir de um fenômeno 'natural' de densificação e hetereogeneidade sociais" (CASTELLS, 1978).

Ao reduzir a análise da cidade à esfera do consumo concentra-a na política urbana do consumo coletivo e na mobilização dos movimentos sociais urbanos, e para tanto a situa em uma linha comum desde o ideo-eco-logismo da Escola de Chicago até a obra de Lefebvre, a quem equipara aos culturalistas.

Para Castells admitir o urbano como um estilo de vida seria admitir o papel da cultura, da superestrutura, na conformação das relações sociais e obscureceria os problemas sociais que se manifestavam nas cidades. Ao fazê-lo, no entanto, deixou de lado a possibilidade de considerar a existência do urbano no não-urbano. Por outra parte, admitir o papel da cultura iria contra as posturas epistemológicas do marxismo ortodoxo e do estruturalismo althusseriano, pois o econômico seria o determinante em última instância, ou seja, em última análise isto representaria um embate contra o primado do economicismo e do historicismo, tão criticados por Lefebvre. Anos mais tarde Touraine (1980) destacaria o papel da cultura na sociedade contemporânea ao contestar o primado do econômico.

Após a publicação da Questão Urbana de Manuel Castells (1972), Jean Lojkine (1977) define, em contraposição a Castells, o urbano enquanto o lugar da produção e da circulação necessário para a reprodução das relações sociais de produção onde interviriam diversos agentes, em particular o Estado. As definições de ambos, todavia a partir de um certo ponto de vista, podem ser vistas como complementares, além de partilharem a perspectiva economicista.

Em decorrência das proposições destes dois autores o urbano passou a ser visto enquanto o produto do capital que requer uma organização espacial e o lugar onde os fatores de reprodução e demanda se concentram. Nesta perspectiva o espaço foi reduzido a mero suporte da circulação de capital, mercadorias e informação enquanto o desenvolvimento das cidades estaria subordinado às necessidades da circulação e à subordinação do trabalho ao capital. ${ }^{2}$ (HARVEY, 1978)

A redução da análise marxista à afirmação das determinações estruturais últimas pode ser interpretada como a eliminação de toda especificidade histórica e geográfica, o que conduz à supressão da cidade e dos processos espaciais, entre eles a urbanização, como objeto de análise. Muitos analistas chegaram a esta conclusão 
nos anos setenta. Nem teorica, nem empiricamente, a cidade era considerada um objeto, mas a expressão de estruturas societárias mais amplas e profundas.

Enfim, Castells chega a colocar que "é necessário substituir a dicotomia rural/urbana por uma diversidade descontínua de formas espaciais e por uma pluralidade diferenciada de unidades de reprodução da força de trabalho" (CASTELLS, 1972). Porém permanece sua identificação com o urbano enquanto local de reprodução da força de trabalho, por relacionar e identificar o modo de vida a uma instância cultural e não ao quadro e condição de vida dos trabalhadores, definidos por sua inserção no processo produtivo.

Apesar de Castells, na década de setenta, não ver no urbano um objeto teórico específico, não deixou de captar a nova problemática urbana que emergia. Foi Harvey, todavia, quem contribuiu para abrir uma nova fase na análise da interação entre o espaço, o urbano e o processo de produção:

Primeiro, ao entrelaçar o trabalhar e o viver e apontar que "o capital domina o trabalho não só no local de trabalho, mas também no espaço de viver, através da definição da qualidade e dos padrões de vida da força de trabalho" (HARVEY, 1982), ou seja a luta entre capital e trabalho extrapola os locais de trabalho, sem que as lutas nos locais de viver extrapolem as lutas nos locais de trabalho, elas ocorrem simultaneamente.

Segundo, ao propor, com base nos Grundrisse de Marx, que a criação de novas estruturas espaciais não seria um processo isento de contradições. Para Marx, o capital no intuito de superar barreiras espaciais impostas pela propriedade fundiária e para suprimir o espaço pelo tempo, procura criar graças ao avanço tecnológico novas estruturas móveis e fixas, meios de transportes, instalações, meios de produção, as quais acabam por atuar, elas mesmas, como barreiras a serem superadas num momento posterior. De onde Harvey conclui que:

O capital assim chega a representar-se a si mesmo na forma de uma paisagem física criada a sua imagem, criada como valores de uso para aumentar a progressiva acumulação de capital em uma escala crescente. A paisagem geográfica que abarca o capital fixo e imóvel é simultaneamente a glória do desenvolvimento pretérito do capital e uma prisão que inibe o avanço posterior da acumulação, porque a própria construção desta paisagem é antitética da 'destruição das barreiras espaciais`' e, enfim, inclusive da eliminação do fator espaço pelo fator tempo (HARVEY, 1978).

\footnotetext{
2 "Em sociedades industriais e capitalistas, as cidades desenvolvem-se de acordo com as necessidades da circulação de capital e mercadorias, e com a subordinação do trabalho ao capital. Apresentamse a si mesmas como o lugar no qual os fatores de reprodução e demanda estão concentrados. Em tal contexto, como foi claramente assinalado por Freitag, é difícil falar de relações sociais urbanas". (LAMARCHE, 1977).
} 
Ao inserir o meio urbano na paisagem geográfica do capital como parte integrante do processo geral de reprodução das relações sociais e condições gerais de produção em escala ampliada, Harvey aponta para a constante construção e dissolução de estruturas móveis e fixas, de espaços socialmente construídos, e conferelhes uma espacialidade complexa e contraditória - uma dimensão espacial em perpétua transformação num processo dialético e contraditório, onde, apesar de necessários, novos espaços tornam-se obstáculos para espaços futuros.

Terceiro, ao situar a importância da mobilidade espacial do capital e do trabalho na conformação do território, não reduz a formação da paisagem apenas ao capital mas aos movimentos do trabalho em sua luta contra os avanços do capital. O fato do capital criar uma paisagem não pressupõe que o trabalho a aceite passivamente, isto portanto "não significa dizer que o trabalho não pode vencer em aspectos particulares, nem implica a existência de uma e apenas uma definição de valores de uso para o trabalho, que se adapte aos interesses da acumulação" (HARVEY, 1982).

A cidade, o espaço urbano, assim passa a integrar a paisagem geográfica do capital enquanto parte necessária de um espaço social complexo e pleno de contradições que simultaneamente estimula e obstaculariza o desenvolvimento e reprodução das relações sociais de produção a nível geral, num movimento de construção de novos espaços e destruição / apropriação de espaços pretéritos.

A ampliação da temática urbana, entre 1970/80, com ênfase, ainda que limitada nas relações espaciais, constituiu uma ameaça ao primado do econômico e da produção em si, conjugada ao receio de se resvalar para o determinismo espacial.

Em consequiência em uma parte dos estudos urbanos e regionais da década de 70 manifestou-se uma reafirmação do historicismo e economicismo onde o espaço passou a ser considerado como "um produto das relações sociais mais fundamentais de produção e das 'leis de movimento' a-espaciais (mas, mesmo assim, histórica) do capital" (SOJA, 1993), e um apêndice interessante a ser considerado na análise.

Muitos estudiosos reviram mais tarde suas posições e retornaram do historicismo à teorização do espaço como Massey, Harvey e Smith. Se a defesa da perspectiva espacial não teve êxito ao menos a análise espacial marxista prosperou como um adendo e ênfase metodológica.

\section{Balanço do debate da vertente crítica}

A controvérsia entre geógrafos, sociólogos, economistas políticos e teóricos do planejamento mobilizados para elaborar uma análise crítica da urbanização capitalista, sobre a possibilidade das formas sociais e espaciais urbanas constituirem-se num objeto adequado de teorização e análise alimentou diversas discussões nas duas últimas décadas. Parece-nos que este debate tem sua raiz exatamente no con- 
fronto disciplinar com distintos viéses analíticos de um mesmo objeto, a partir de uma mesma base teórica, que procuravam enfatizar e privilegiar o que lhes parecia crucial.

O althusserianismo de Castells levou-o a rechaçar Lefebvre e atribuir-lhe uma fetichização do urbano. Porém, parece-nos que Lefebvre ao invés de fetichizar o urbano desenvolvia uma tese mais geral, não compreendida então por Castells, de que as lutas contemporâneas, sociais ou não, eram intrinsecamente disputas pela produção social do espaço, ao propor que "se o espaço se torna lugar da re-produção (das relações de produção), torna-se também lugar de uma vasta contestação não localizável, difusa, que cria o seu centro às vezes num sítio e logo noutro". (LEFEBVRE, 1973).

Esta contestação, conforme Lefebvre, estaria ligada às necessidades de "ocupação do mundo pelo crescimento econômico, pelo mercado e pelo Estado (capitalista ou socialista)" (LEFEBVRE, 1973). Nesta perspectiva os movimentos sociais urbanos, definidos por Castells como uma nova forma de luta política, constituíam apenas uma parte da problemática espacial mais ampla de Lefebvre, que manteve-se como a única voz discordante ao salientar a necessidade de uma problemática espacial no marxismo contemporâneo, por considerar que a transformação do capitalismo estaria relacionada a uma luta simultaneamente espacial e social, numa dialética horizontal e vertical, sem se poder aceitar a priorização ou determinação de uma sobre a outra.

Algumas destas análises tendiam a reduzir a urbanização a um fenômeno do modo de produção capitalista, e esqueciam que antes do surgimento do capitalismo já havia cidades e urbanização, desde que existe uma divisão social e territorial do trabalho. Não se trata, obviamente, sempre da mesma urbanização. No decorrer do processo histórico ela muda de qualidade e significado conforme se transforma o meio técnico-científico. Ou seja, a estruturação do território, da qual a urbanização é parte integrante, não é estática, mas muda de caráter em termos de peso e significado/qualidade.

O que não se percebia é que a urbanização, longe de ser um processo autônomo, era parte integrante e essencial da produção do espaço pelo capitalismo, ao mesmo tempo em que obstacularizava seu desenvolvimento num movimento dialético.

Se, durante o capitalismo competitivo, pouca importância foi atribuída, ao contexto urbano, isto mudou de figura com a reprodução ampliada, globalização da economia e desenvolvimento do meio técnico-científico, que intensificou a concentração de capital nos centros industriais e criou uma pressão crescente por parte do capital e da força de trabalho por investimentos em infra-estrutura, melhoria da habitação, serviços, etc... Era necessário reorganizar o espaço urbano e tornar os sistemas urbanos eficazes tanto para implementar a acumulação de capital quanto para apaziguar a inquietação social. Neste sentido, o Estado desempenhou um papel chave no (re)planejamento das cidades e em sua adequação às novas necessidades que se antepunham ao desenvolvimento do capitalismo. 
A discussão da propriedade da inserção do espaço na teoria social crítica prosseguiu com novas contribuições de geógrafos (Harvey, Soja, Santos e outros), a despeito da controvérsia gerada por Castells, criticado por Lojkine e outros autores. O espaço enquanto categoria de análise acabou por ser incorporado, ainda que parcialmente, por alguns sociólogos como Giddens, Urry e mesmo Castells. Este, no seu trabalho sobre a cidade e os movimentos de base (grassroots) quase acolhe as proposições de Lefebvre, ao colocar que "o espaço não é um 'reflexo da sociedade', ele é a sociedade"; e a ação social sobre o espaço "será exercida numa forma espacial já herdada, produto da história anterior e sustentáculo de novos interesses, projetos e sonhos" (CASTELLS, 1983). .

Harvey e Castells convergem em sua crítica a Lefebvre e ao procurarem delimitar a análise espacial enquanto uma reação à aparente excessiva centralidade e autonomia conferida por Lefebvre à problemática do espaço urbano, a qual lhes parecia relegar a um segundo plano as relações sociais de produção (produção e circulação, reprodução) e do capital industrial, submersas pelas relações sociais espaciais da produção e do capital financeiro. Ambos, todavia, reconhecem a contribuição de Lefebvre para a compreensão da organização do espaço como produto material e do conteúdo ideológico do espaço social. Ou seja, conforme Soja, "em sua conceituação do urbanismo, Lefebvre lhes parecia estar substituindo o conflito de classes pelo conflito espacial / territorial como força motivadora da transformação social radical" (SOJA, 1993).

Lefebvre em sua obra sobre a produção do espaço, entretanto, não coloca a luta de classes e as relações de produção num plano secundário em relação às relações espaciais de produção, mas num mesmo plano, e não limita a reprodução geral das relações sociais de produção apenas a uma esfera (da produção, da circulação ou do consumo). Para Gottdiener (1993) o problema residiria no fato de Harvey e Castells haverem trabalhado com obras de Lefebvre anteriores à Produção do Espaço, onde Lefebvre delineia melhor suas proposições. A raiz do equívoco segundo Soja, estaria "na incapacidade dos analistas marxistas de avaliarem o caráter essencialmente dialético das relações sociais e espaciais, bem como de outras esferas estruturalmente ligadas, como a produção e o consumo." (SOJA, 1993).

A discussão, assim, ao invés de trabalhar a nível de uma dialética sócio-espacial, através da oposição, unidade, contradição e complementariedade, voltou-se para um debate de categorias relativas à primazia do social sobre o espaço. Neste sentido a dialética sócio-espacial, conforme Soja, não se enquadraria nem na alternativa da organização do espaço (no contexto do urbanismo) ser "uma estrutura separada, com suas leis próprias de transformação interna e construção" nem "a expressão de um conjunto de relações inserido numa estrutura mais ampla (como as relações de produção), ambas propostas por Harvey (SOJA, 1993). 


\section{Urbanização e estruturação do território}

A partir da trajetória examinada podemos reafirmar que as relações sociais de produção não se processam no vazio, mas em espaços determinados e assumem um caráter espacial; as relações espaciais de produção (horizontais) são vazias de significado sem relações sociais de produção (verticais) que as qualifiquem. Há que se perceber o caráter dialético destas relações onde uma pressupõe a outra, ambas dialeticamente inseparáveis interdependentes e contraditórias.

Para superar a tendência da postura historicista, em bloquear o papel do espaço social no território e reduzi-lo ao papel do lugar do processo histórico, há que se considerar uma série de premissas, conforme Soja, nas quais operamos algumas modificações:

1. O espaço social é produto de uma sociedade; como tal é ao mesmo tempo meio e resultado das ações e relações sociais, o que lhe confere um caráter dialético. A estruturação espaço-temporal da vida cotidiana interfere e condiciona a concretização e constituição das ações e relações sociais.

2. A constituição do espaço socialmente produzido é plena de contradições e lutas, muitas rotinizadas no cotidiano, decorrentes do caráter dialético de sua produção, através da atividade social e econômica, por ser simultaneamente suporte, meio, produto e expressão da reprodução das relações sociais de produção em escala ampliada, o que confere a estas relações um caráter espacial necessário.

3. O espaço socialmente produzido é simultaneamente fruto das tensões entre capital e trabalho e de estratégias de luta pela reprodução do capital e do trabalho, bem como de práticas sociais organizadas que visam antagonicamente quer a manutenção do espaço social existente, quer uma transformação radical deste espaço.

4. O espaço socialmente produzido condensa em si desde a quotidianeidade do viver até a história, nele se mesclam marcas de tempos passados e persistem e coexistem, conforme o caso, formas capitalistas e pré-capitalistas de produção. Neste sentido não há como realizar uma interpretação materialista da história sem uma concomitante interpretação do espaço social e vice-versa.

A produção do espaço social e os processos históricos e sociais não se desenrolariam alheios entre si, mas num jogo de interação, oposição, contradição. Por conseguinte, a estruturação do território poderia ser definida dialeticamente como um elemento substantivo das relações gerais de produção simultaneamente sociais e espaciais, necessária para o próprio processo de produção no arranjo dos territórios e na distribuição desigual e hierarquizada das classes sociais e das atividades produtivas no espaço que levam a uma diferenciação social e espacial que contribui 
para um desenvolvimento desigual e combinado em diferentes escalas, a nível espacial e de relações de dominação.

Neste sentido a urbanização seria uma forma de estruturação do território, onde o peso dos lugares varia historicamente em função dos condicionantes e processos sociais, econômicos, políticos, e por vezes culturais que tomam corpo. E a rede urbana seria a expressão cristalizada de diferentes estruturações do espaço em diferentes tempos históricos.

Isso nos leva a adotar a concepção ampliada de urbanização, proposta por Giddens (1989), que a partir da compreensão de que o espaço não deve ser entendido apenas como algo (um continente) a ser preenchido por populações organizadas social, econômica e politicamente, define a urbanização enquanto o processo social de maior significância na estruturação do território. Soja amplia esta proposição ao afirmar que

A urbanização pode ser vista como uma de várias grandes acelerações do distanciamento espaço-tempo ... A especificidade do urbano é definida, pois, não como uma realidade separada, com suas próprias regras sociais e espaciais de formação e transformação, ou meramente como um reflexo e uma imposição da ordem social. O urbano é uma parte integrante e uma particularização da generalização contextual mais fundamental sobre a espacialidade da vida social... Em sua...especificidade social, o urbano é permeado por relações de poder, relações de dominação e subordinação, que canalizam a diferenciação regional e o regionalismo, a territorialidade e o desenvolvimento desigual, e as rotinas e revoluções, em muitas escalas diferentes. (SOJA, 1993).

\section{A escala territorial da urbanização}

A maioria das concepções de urbano e urbanização enfocadas converge para duas visões polares: o urbano enquanto lugar da reprodução da força de trabalho e das relações sociais no cotidiano que se expressam através do consumo; e o urbano enquanto lugar da reprodução das relações sociais de produção na perspectiva da reprodução dos bens de produção.

Lefebvre, por sua vez, chama a atenção para o fato de que o urbano é o espaço onde se processam estas duas esferas de reprodução, que historicamente se concatenam em diferentes graus e intensidades conforme o estágio de desenvolvimento das forças produtivas, concernente principalmente ao desenvolvimento do meiotécnico-científico. O território, todavia, não é apenas o continente destas relações; para Lefebvre o caráter espacial destas relações cria historicamente um espaço social que condiciona o desenvolvimento futuro destas relações. 
Durante o capitalismo competitivo o espaço urbano condensou e concentrou estas duas esferas de reprodução, dadas as limitações do meio técnico-científico em termos de transportes e comunicações. Hoje, entretanto, pode-se observar a tendência à separação crescente entre as localizações espaciais destas duas esferas de reprodução. (CASTELLS e HALL, 1994).

\section{As transformações em curso e seus desdobramentos para a análise urbana}

O problema que se impõe no presente é o teor das transformações na matriz espacial - temporal da organização social, empresarial e territorial decorrentes das revoluções informacional, genética e energética, que tendem a tornar nosso instrumental analítico obsoleto e contribuem para gerar um novo paradigma que nos leva a considerar o urbano em escala territorial.

A resultante fragmentação espacial de empresas e de grupos sociais articulados mediante a formação de novas redes dá margem ao surgimento de novas solidariedades e territorialidades, as quais incidem diretamente sobre a distribuição das atividades produtivas e da população no território.

No âmbito da distribuição das atividades produtivas, conduzem a uma reestruturação horizontal e vertical da produção que resulta em uma reestruturação territorial, com uma abrangência da escala global à local.

No âmbito da distribuição da população, contribuem para alterar substancialmente as condições de vida de diferentes assentamentos em diversos pontos do território, em função seja de sua localização estratégica frente às novas redes de comunicação e transportes, seja pela integração e/ou não integração aos fluxos empresariais e da produção.

Pode-se dizer que as transformações em curso representam novas estratégias para a acumulação e criam novas condições para a mobilidade do capital e novos obstáculos à mobilidade espacial da força de trabalho.

Análises recentes (Storper, Walker, Scott, Lipietz, entre outros) caracterizam a nova distribuição das atividades produtivas enquanto um dos fatores da reestruturação territorial. Seu recorte analítico leva-as a privilegiar os aspectos e efeitos da reestruturação vertical (escala hierárquica de produção) e horizontal (amplitude espacial) da produção nas empresas, nas relações de trabalho e seus desdobramentos espaciais (territoriais) através da terciarização, da formação de novas redes empresariais e das novas localizações. Dada sua ênfase na esfera da produção e circulação, a maior parte destes trabalhos desconsidera o que acontece em termos da distribuição da população (trabalhadores urbanos, agrícolas, empresários, etc.). 


\section{Condicionantes da estruturação territorial}

As transformações sócio-espaciais na distribuição das atividades produtivas e da população, materializadas espacialmente enquanto formas de desenvolvimento urbano, em diferentes níveis e escalas, seriam resultantes tanto da lógica da ação do Estado, de distintos capitais (empresas), entre eles o industrial, agro-industrial e em particular o imobiliário, quanto das estratégias de localização e distribuição da força de trabalho.

Há que se considerar que na estruturação territorial - distribuição das atividades produtivas e da população (diferentes classes sociais) - interferem, além da ação das empresas e das diferentes classes sociais, de distintas maneiras, três lógicas ligadas à ação: do Estado, do setor imobiliário e da capitalização da agricultura, entre outras.

A ação destas lógicas isoladas ou combinadas, conforme a conjuntura e as especificidades de cada lugar, tende a gerar um novo padrão de liberação da força de trabalho, que foge ao esquema clássico de proletarização total, característico das etapas anteriores do capitalismo.

Os pequenos proprietários e trabalhadores "liberados" das relações tradicionais de produção ao invés de se dirigir, conforme o processo clássico, para as cidades e se assalariar em atividades urbanas, tendem a se ocupar em atividades rurais e urbanas e tornar-se uma força de trabalho sazonal dedicada tanto a atividades urbanas quanto primárias. Contribuem, assim, para alterar o padrão de assentamento nas pequenas, médias e grandes aglomerações urbanas seja ao manter suas pequenas propriedades seja ao tender a se localizar nas periferias urbanas ou em pequenos aglomerados. (SANTOS, 1993).

A lógica do setor imobiliário acirra estes movimentos. A perspectiva de usos potenciais propicia a valorização do solo em áreas urbanas e rurais o que leva a uma expulsão dos trabalhadores urbanos das cidades e dos trabalhadores rurais das áreas agrícolas. Resulta daí tanto um aumento da população rural em áreas urbanas situadas em áreas onde a produção agrícola se capitaliza, quanto uma tendência a trabalhadores urbanos se radicarem em áreas rurais ${ }^{3}$

Tais movimentos estariam ligados a estratégias de sobrevivência e a mobilidade espacial da força de trabalho. Isto vai ao encontro da hipótese alternativa ao modelo clássico marxista de proletarização total e liberação repentina dos meios de produção e conformação de um exército industrial de reserva tipicamente urbano proposta por Becker (1988) a partir da análise dos processos espaciais na fronteira. Na atual etapa do capitalismo e de conformação de complexos agroindustriais a mobilidade espacial e setorial do trabalho passaria a ser uma condição necessária para a constituição de

\footnotetext{
${ }^{3}$ Processos descritos por BECKER (1982) e MACHADO (1982, pp. 182-183) para áreas de fronteira e por SANTOS, (1993) com relação às agrovilas.
} 
um mercado de trabalho regional na fronteira. Oliveira (1977) já assinalara a tendência à fluidez do exército industrial de reserva entre as atividades rurais e urbanas.

O estudo da urbanização no atual momento, portanto, deve contemplar o papel da mobilidade do capital e do trabalho, na medida em que sua intensificação contribui para alterar a distribuição das atividades produtivas e das diversas classes sociais no território.

A mobilidade do trabalho constitui-se, segundo Gaudemar (1976), em condição necessária, senão suficiente da gênese do capital e indício de seu crescimento; expressa na (re)produção da força de trabalho, em sua utilização no processo produtivo, em sua circulação espacial e ocupacional, e em sua liberação que compreenderia tanto a transformação do campesinato em trabalhadores assalariados rurais e/ou urbanos quanto a constituição de camadas intermediárias. Configura-se, portanto, como fruto das estratégias de diversos agentes sociais, entre eles o Estado e as empresas, para moldar mercados de trabalho regionais.

A livre mobilidade espacial da força de trabalho e sua fácil adequação constituise em condição necessária à circulação do capital no espaço. Paradoxalmente, por preferirem uma parcela da força de trabalho estável num território delimitado, os capitalistas individuais tendem a apoiar ações estatais que restrinjam a livre mobilidade da força de trabalho (HARVEY, 1985).

As transformações recentes, a reengenharia industrial, acompanhada da modernização da agricultura aumentaram a mobilidade setorial e espacial do trabalho e fragmentaram a estrutura de classes com uma ampliação da margem de pobreza.

$\mathrm{Na}$ atual conjuntura a existência de uma força de trabalho polivalente coloca um limite à proletarização total e torna-se condição necessária para a organização de um mercado de trabalho regional. A mobilidade espacial e setorial da força de trabalho, concretizada em ocupações sazonais possibilita a complementação da renda dos trabalhadores e permite compatibilizar a contradição entre a necessidade de atrair força de trabalho sem lhe dar legalmente a terra e a necessidade de dar a terra para produção de alimentos (subsistência) e diminuir as tensões sociais.

Os trabalhadores para melhorar seus salários e condições de vida e trabalho podem se organizar coletivamente, construir suas próprias infra-estruturas sociais e fisicas, lutar pelo controle do aparato de estado, e conforme obtenham sucesso veêmse em condições de suportar restrições à livre mobilidade geográfica da força de trabalho. Caso contrário, tenderão a buscar maximizar sua mobilidade espacial através de migrações. Em caso de sucesso das reivindicações dos trabalhadores em espaços delimitados, o capital tende a se evadir gradativamente e migrar para outras áreas.

Em síntese, frente às novas condições espaciais da produção os diversos capitais buscam maximizar suas respectivas mobilidades e tornar-se quase que independentes do espaço, enquanto os trabalhadores procuram maximizar sua mobilidade espacial através de diferentes estratégias no âmbito das relações de trabalho e de sobrevivência no cotidiano. Temos, assim, movimentos antagônicos, entre capital e trabalho e entre diferentes capitais, para maximizar suas respectivas mobilidades, 
mediados pela ação do Estado em dotar o espaço de infra-estrutura (meios de abastecimento e comunicação).

\section{Esferas de (re)produção e urbanização}

Essas mobilidades traduzem-se em duas esferas de (re)produção voltadas para a satisfação das necessidades respectivamente do capital e da força de trabalho, ambos com diversas frações com distintas lógicas e movimentos, que se concretizam espacialmente na produção de distintos espaços de trabalho e vida, que atravessam a esfera de reprodução social no cotidiano.

A urbanização, assim, hoje, poderia ser compreendida como a concatenação e concretização espacial destes movimentos, de reprodução e distribuição das atividades produtivas e da população, em disputa pelo espaço, que sob o capitalismo traduzem-se nas estratégias do capital e do trabalho para garantir suas respectivas reproduções. As diferenças de intensidade e de articulação entre estes processos variam historicamente e conformam a estruturação da produção e do território.

A urbanização, via de regra, é enfocada como resultante de um destes processos de reprodução, preferencialmente o da reprodução das relações de produção, que são hegemônicas. Se estas esferas de (re)produção caminharam combinada e antagonicamente em um espaço comum durante o capitalismo competitivo, hoje há uma tendência a maximizar sua separação. $\mathrm{O}$ desenvolvimento do meio técnicocientífico propicia que deixe de haver necessariamente uma coincidência espacial no território destas duas esferas, que tendem a se tornar independentes da aglomeração.

Estes movimentos conjugados às lógicas abordadas (do Estado, do capital imobiliário e agro-industrial) e o desenvolvimento do meio técnico-científico, tendem a gerar uma exclusão social e espacial dos trabalhadores e uma fragmentação do espaço que se expressa em uma diferenciação e especialização dos lugares a nível territorial, com cidades voltadas ou para a produção, o consumo ou a moradia. Parece-nos, portanto, que a conjugação destes dois movimentos (do capital e do trabalho) resulta em uma estruturação do território que atinge as velhas formas de urbanização.

A disseminação no território de relações espaciais e sociais de produção de caráter urbano - enquanto relações que o capital (entendido aqui enquanto um conjunto de diferentes capitais em disputa pela hegemonia) e o trabalho (entendido aqui enquanto um corpo de diferentes categorias sociais) travam com o meio (o espaço) para garantir suas respectivas reproduções e necessidades - tende a conferir ao urbano uma amplitude territorial; isto é, uma amplitude que transcende (ultrapassa) aquilo que percebemos como "perímetro urbano".

O urbano poderia, assim, ser considerado não-simultaneamente tanto o lugar da reprodução das relações de produção, referentes aos bens e meios de produção, quanto o lugar da reprodução da força de trabalho. 
O confronto entre estas esferas é antigo, não se trata de resolvê-lo aqui. Para a análise da urbanização ser completa, deveria abranger estes dois movimentos. Tomar em conta apenas o lado da produção significaria reduzir a urbanização a uma determinação do econômico e atribuir a estruturação do território apenas à esfera da produção. O mesmo vale em contrapartida se considerarmos apenas os aspectos ligados à população. Entretanto não podemos desconsiderar a farta produção teórica sobre a estruturação territorial do ponto de vista da produção.

A nível do capital o urbano se espraia como novas formas de apropriação e ocupação do espaço, que resulta em uma estruturação territorial da produção. A nível da força de trabalho o urbano dissemina-se como um modo de vida, que tem por base o quadro de vida dos trabalhadores e sua efetiva inserção na produção e que conduz a uma redistribuição territorial da população. A combinação desta estruturação e distribuição transforma a face do território e engendra (nov)os padrões de urbanização.

\section{Os lugares da urbanização}

O entrelaçamento e encontro espacial das diferentes lógicas apontadas e dos movimentos das esferas de reprodução (de diversos capitais, por vezes em conflito, e de diversas classes e frações de classe sociais com interesses distintos) em confronto pelo espaço propicia o surgimento, em diferentes escalas, de pontos (lugares) no território, o que vai ao encontro da proposição de Santos de que "cada lugar ... é ponto de encontro de lógicas que trabalham em diferentes escalas, reveladoras de níveis diversos, e às vezes contrastantes ..." (SANTOS, 1994).

Estes pontos (lugares) - através de suas interações ou não-interações e de seus desenvolvimentos variáveis, em uma rede espacial de pontos especializados hierárquicos e multiestratificados - contribuem para a regionalização do território e da sociedade. Esta regionalização, segundo Giddens, "constituir-se-ia em torno das conexões, tanto de interdependência quanto de antagonismo, entre a cidade e o campo" (GIDDENS, 1989). conforme se configuram o que caracteriza como contextos de co-presença, definidos por modos variáveis de interseção de presença e ausência de integração social.

Consoante com esta perspectiva, os lugares poderiam ser considerados uma manifestação espacial da apropriação do espaço e da natureza pelo homem, que é inseparável da transformação da sociedade no tempo e no espaço; enfim, poderiam ser entendidos como pontos de concentração de condições gerais.

Estes pontos tornam-se lugares ao permitirem que haja um entrelaçamento e aglomeração de atividades permanentes e estáveis que os tornem centrais, nodais, estratégicos, para as interações intra-territoriais e para as diferentes lógicas que estruturam o território em tempos históricos delimitados. Na escala intra-urbana, historicamente, os pontos predominantes da co-presença social (Giddens) seriam os lugares de residência e de trabalho. Se em contextos menos modernos esses locais são concentrados em contextos mais avançados ou em transformação, ten- 
dem a se distanciar e se separar, em escalas que vão do local ao territorial. Neste sentido estas localidades constituiriam a base da urbanização. Assim,

As vilas e cidades podem ser descritas como localidades que abrangem contextos, recintos e concentrações nodais da interação humana, ligados à integração social e dos sistemas $e$, por consegüinte, a redes múltiplas de poder social. No contexto do mundo contemporâneo, a localidade pode ir desde os menores povoados ou bairros até as maiores conurbações (SOJA, 1993).

Estes lugares, pontos nodais, todavia, podem não se converter em aglomerações urbanas, e isto irá depender necessariamente dos graus e tipos de interações que estabeleçam entre si e outras áreas do território, em diferentes níveis e escalas.

\section{As escalas da urbanização}

Giddens relaciona o espaço e a urbanização ao afirmar que "o espaço não é uma dimensão vazia ao longo da qual agrupamentos sociais vão sendo estruturados, mas deve ser considerado em função do seu envolvimento na constituição de sistemas de interação" (GIDDENS, 1989). O espaço se transforma conforme se desenvolve o meio técnico-científico e modificam-se as formas de apropriação da natureza pelo homem. Em um determinado momento histórico temos a cidade limitada à aglomeração física, e com uma identidade comum ao urbano. Todavia, concordamos com Giddens que

Tais cidades, (...) não existem ainda no tempo e espaço mercantilizados. A compra e venda do tempo - como tempo-trabalho - é certamente um dos mais marcantes traços do capitalismo moderno... A mercantilização do tempo, engrenada aos mecanismos da produção industrial, põe por terra a diferenciação da cidade e do campo, característica de sociedades divididas em classes... Junto com a transformação do tempo, a mercantilização do espaço estabelece um 'ambiente criado' de caráter distinto - expressando novas formas de articulação institucional. Tais novas formas de ordem institucional alteram as condições de integração social e do sistema, e portanto modificam a natureza das conexões entre o próximo e o remoto no tempo e no espaço (GIDDENS, 1985).

As transformações presentes do meio técnico científico, dos novos meios de comunicação e transporte, ao vencer o espaço pelo tempo favorecem uma crescente desaglutinação espacial de atividades e permitem uma separação de locais de trabalho, residência e consumo em uma escala mais ampla do que a cidade pro- 
priamente dita. Tende a diminuir a necessidade de diversas pessoas trabalharem num mesmo local para uma empresa funcionar, e o mesmo no concernente às suas moradias. E tende a aumentar a dissolução entre o rural e o urbano.

Ocorre uma especialização (separação) de lugares na escala do território com a multiplicação de núcleos dormitório, centros de consumo e centros de produção não necessariamente coincidentes e aglutinados.

A urbanização, assim, tende a deixar de estar relacionada apenas à urbe, ao urbano, à cidade, à aglomeração de pessoas, equipamentos e infra-estruturas. A urbanização tende a assumir uma forma pulverizada em segmentos dispersos e conquista desta maneira fragmentada a escala do território - e passa a se referir também a processos gerais e sócio-econômicos no meio rural (se é que ainda hoje podemos falar de uma dicotomia rural-urbano).

O urbano torna-se "uma parte integrante e uma particularização da generalização mais contextual mais fundamental sobre a espacialidade da vida social, a de que ocupamos uma matriz espacial multiestratificada de locais nodais" (SOJA, 1993). e passa a estar relacionado a um modo de vida, enquanto quadro e condição de vida (inserção no processo produtivo), não na acepção restrita de Wirth, e sim numa acepção mais ampla, onde não só a cultura mas outros fatores sociais, econômicos, políticos e espaciais interferem nas relações que os homens travam entre si e o meio em que vivem. A aglomeração não deixa de ser importante, porém, sua permanência dependerá do desenvolvimento do meio técnico-científico e das transformações das relações de trabalho e de vida.

Neste sentido concordamos com a proposição de Santos de que:

Estaríamos, agora, deixando a fase da mera urbanização da sociedade, para entrar em outra, na qual defrontamos a urbanização do território. A chamada urbanização da sociedade foi o resultado da difusão, na sociedade, de variáveis e nexos relativos à modernidade do presente, com reflexos na cidade. A urbanização do território é a difusão mais ampla no espaço das variáveis e dos nexos modernos (SANTOS, 1993).

As cidades seriam, neste contexto, mais que um meio físico, aglomerações nodais especializadas, socialmente criadas, parte de um sistema multiestratificado de pontos nodais e de uma configuração raras vezes hierárquica de locais diferenciados, cujas formas e funções variam tanto no tempo quanto nos lugares.

Se as cidades como as conhecemos tendem a desaparecer, se a organização espacial da população e das atividades produtivas está em transformação em todas as escalas em diversos pontos, isto resultaria no surgimento de novos padrões de assentamento e distribuição da população e das atividades produtivas, ou seja, de novos padrões de urbanização. 


\section{REFLEXŌES SOBRE O ESPAÇO, O URBANO E A URBANIZAÇÂO}

Resumo: Trata-se de discutir se a urbanização é passível de ser compreendida como parte do processo geral de estruturação da sociedade e do território. Um processo onde as desigualdades sociais e espaciais conjugadas à mobilidade espacial e setorial do trabalho contribuem para alterar o território. Este processo que cria fixos e fluxos tem uma resultante espacial em duas escalas: a cidade, na escala dos lugares; e a rede urbana, enquanto a manifestação espacial da cooperação entre lugares, na escala territorial. Isto não significa dizer que a urbanização em si é um determinante maior ou menor, mas um produto de práticas socais que interage com outros fatores na construção do espaço social além das cidades.

Palavras-chave: Urbanização, Reprodução espacial, Reestruturação

\section{REFLECTIONS ON SPACE, URBAN AND URBANIZATION}

Summary: Our goal is to argue whether the urbanisation could be understood as a part of society and territory general structuring process. A process where the social and spatial inequalities articulated to spatial and sectorial mobility of labor contribute to transform the territory. This process that creates fix and flows has an spatial outcome in two scales: the city at the place scale and the urban network, as a spatial manifestation of the cooperation among places, at the territorial scale. Not meaning that urbanization by itself is a major or minor determinant, but a social practices product, which interacts with other factors on the construction of social space beyond the cities.

Keywords: Urbanization, Space reproduction, Restructuring

\section{BIBLIOGRAFIA}

BECKER, B.K. (1982): The State and the Land Question on the Frontier. In: Contribution to the Latin American Regional Conference. Rio de Janeiro: IGU - IBGE.

CASTELLS, M. (1978) [1972]: La Cuestión Urbana. México: Siglo Veintiuno. (1983): The City and the Grass Roots. Los Angeles: University of California.

CASTELLS, M. \& HALL, P. (1994): Technopoles of the World. Londres: Routledge.

GAUDEMAR, J. (1976) [1979]: Movilidad del Trabajo y acumulacion de capital. México: Era.

GIDDENS, A. (1989): A Constituição da Sociedade. São Paulo: Martins Fontes. (1985): Time, Space and Regionalisation. In: GREGORY, D. e URRY, J. (ed.): Social Relations and Spatial Structures. Londres: MacMillan, Cambridge.

HARVEY, D. (1978): La Geografia de la acumulacion capitalista: una reconstrucción de la teoria marxista. In: GARCIA, M.D. (ed.). La Geografia Regional Anglosajona. Bellaterra: Universidad Antonina de Barcelona.

(1982): O trabalho, o capital e o conflito de classes em torno do ambiente construído nas sociedades capitalistas avançadas. Espaço \& Debates. São Paulo: Cortez, ano II, nº 6, jun-set, pp. 6-35. 

(1985): The Geopolitics of Capitalism. In: GREGORY, D. e URRY, J. (ed.). Social Relations and Spatial Structures. Londres: Mac Millan, Cambridge.

LAMARCHE, F. (1977): Property development and the economic foundations of the urban question. In: PICKVANCE, C.G. (ed.): Urban Sociology: critical essays. Londres: Tavistock Publications.

LEFEBVRE, H. (1972) [1970]: La Revolución Urbana. Madrid: Alianza. (1976) [1972]: Espacio y Politica. Barcelona: Peninsula. (1973): A Re-Produção das Relações de Produção. Porto, Escorpião (1 ${ }^{\mathrm{a}}$ parte de La Survie du Capitalisme). Paris: Anthropos. (1991) [1974]: The Production of Space. Oxford (R.U.) e Cambridge (EUA): Blackwell.

LOJKINE, J. (1981): O Estado Capitalista e a Questão Urbana. São Paulo: Martins Fontes.

MACHADO, L.O. (1982): Urbanization and Migration in Legal Amazonia. In: Contribution to the Latin American Regional Conference. Rio de Janeiro: IGU - IBGE.

OLIVEIRA, F. (1977): A Economia da Dependência Imperfeita. Rio de Janeiro: Graal.

SANTOS, M. (1993): A Urbanização Brasileira. São Paulo: Hucitec. . (1994): Técnica, Espaço, Tempo. São Paulo: Hucitec.

SOJA, E. (1993): Geografias Pós-Modernas - a reafirmação do espaço na teoria social crítica. Rio de Janeiro: Zahar. 